\title{
BMJ Open Regional variations and prevalence of psoriasis in Germany from 2010 to 2017: a cross-sectional, spatio-epidemiological study on ambulatory claims data
}

Valerie Andrees, Sandra Wolf, Matthias Augustin, Nicole Mohr, Jobst Augustin

To cite: Andrees V, Wolf S, Augustin M, et al. Regional variations and prevalence of psoriasis in Germany from 2010 to 2017: a cross-sectional, spatio-epidemiological study on ambulatory claims data. BMJ Open 2021;11:e047806. doi:10.1136/ bmjopen-2020-047806

- Prepublication history for this paper is available online To view these files, please visit the journal online (http://dx.doi org/10.1136/bmjopen-2020047806).

Received 09 December 2020 Accepted 19 October 2021

Check for updates

(C) Author(s) (or their employer(s)) 2021. Re-use permitted under CC BY-NC. No commercial re-use. See rights and permissions. Published by BMJ.

Institute for Health Services Research in Dermatology and Nursing (IVDP), University Medical Center HamburgEppendorf (UKE), Hamburg, Germany

Correspondence to Dr Jobst Augustin; jo.augustin@uke.de

\section{ABSTRACT}

Objectives Global prevalence rates of psoriasis differ significantly, with lowest rates in the equator region and increasing tendencies towards the north but also differences within-country. Information on regional variations in Germany is missing. This study aims to analyse the change of psoriasis prevalence in Germany over time and to detect regional variations.

Design Cross sectional, spatio-epidemiological study on regional psoriasis prevalence in Germany.

Setting Claims data study based on nationwide outpatient billing data on county level.

Methods Analyses based on outpatient billing data for 2010-2017 derived from all people insured in statutory health insurances (about 72.8 million). We performed descriptive spatio-temporal analyses of prevalence rates using probability mapping and statistical smoothing methods, identified spatial clusters and examined a northsouth gradient using spatial statistics.

Results The prevalence increased from 147.4 per 10000 in 2010 to 173.5 in 2017. In 2017, counties' prevalence rates ranged between 93.8 and 340.9. Decreased rates occurred mainly in southern counties, increased rates in northern and eastern counties. Clusters of low rates occur in southern and south-western Germany, clusters of high rates in the north and north-east. The correlation between counties' latitudes and their prevalence rates was high with Pearson's $r=0.65(p<0.05)$.

Conclusion Increased prevalence of psoriasis over time and marked regional variations in Germany were observed which need further investigation.

\section{INTRODUCTION}

Psoriasis is a very common chronic inflammatory skin disease with high impact on patients' health and quality of life. ${ }^{1}$ The disease typically involves thick pruritic plaques and can affect nails and joints. ${ }^{1}$ Psoriasis often occurs with other serious comorbidities, such as depression, diabetes or hypertension. ${ }^{1}$ Severe psoriasis is associated with higher mortality. ${ }^{2}$ Some countries show increasing prevalence rates of psoriasis over the last decade, ${ }^{3}$ which is assumed to be a worldwide phenomenon. However, those prevalence estimates differ
Strengths and limitations of this study

- This study is based on a unique data set, which covers all statutory health insured people which are approximately $90 \%$ of the German population.

- Multidisciplinary methods from the fields of epidemiology, geography and spatial statistics were used to answer the research questions about the regional variation of psoriasis prevalence in Germany.

- The use of outpatient billing data, which are not 'epidemiological prevalences', is limiting.

- Counties as a spatial level are not small enough to make further detailed statements on regional variation.

widely regionally, with national rates of $0.51 \%-11.43 \%$ in adults and $0 \%-2.1 \%$ in children. ${ }^{4-6}$ On the one hand, those geographical variations may be explained by different case definitions in prevalence studies. On the other hand, they can be attributed to different ethnicities, environmental factors and demographic characteristic. ${ }^{3-578}$ Lacking data on the prevalence of psoriasis in many countries impede conclusions about regional differences. ${ }^{4}$ However, some studies suspect a latitudinal trend, with a positive correlation between prevalence and distance from the equator. ${ }^{5}{ }^{6}$ Variations not only occur across countries but are also observed within one country, when applying a consistent case definition. ${ }^{810}$ Springate et al detected a regional trend in the UK: Both the prevalence and incidence of psoriasis were following a latitudinal trend, with increasing cases northwards.

In order to plan the best possible care for psoriasis and to distribute resources efficiently, it is important to provide politicians and decision-makers with precise and up-todate data on the prevalence and distribution of psoriasis. Here, methods of spatial epidemiology and geographical information can give important information. ${ }^{11} 12$ For 
Germany, there have not been such analyses conducted to date despite population-based epidemiological studies being indispensable.

Therefore, this study aims to (1) analyse the change in the regional prevalence of psoriasis in Germany over time and (2) detect regional variations in the prevalence of psoriasis in Germany.

\section{METHODS}

\section{Data set and data preparation}

Nationwide ambulatory claims data on statutory health insured people were provided by the National Association of Statutory Health Insurance Physicians (German: Kassenärztliche Bundesvereinigung, KBV). In Germany, approximately $90 \%$ of the population $(\sim 70000000$ people) is covered by statutory health insurance, ${ }^{13}$ and therefore, represented in this data set. The remaining $10 \%$ are privately insured people. The provided data set comprises information on billed diagnoses (primarily by dermatologists and general practitioners in the ambulatory sector) according to International Classification of Diseases (ICD)-10 for psoriasis (L40.0-L40.9), from 2010 to 2017 at county level (Nomenclature des unités territoriales statistiques, NUTS 3). We excluded L40.5 (psoriasis arthritis) in the analysis because it is a comorbidity of psoriasis. To avoid overestimation of prevalence due to misdiagnosis, we defined cases as at least two billed confirmed diagnoses of psoriasis in different quarters within the year (M2Q definition). We included individuals whose sex and year of birth could be clearly determined and who were not older than 110 years. The regional classification of patients is according to the place of residence of the patients in the respective period on county level as of 2011 with 402 counties. All statistical and spatial analyses were performed with ArcGIS V.10.3.1 (ESRI, Redlands, California, USA), QGIS V.3.10 A Coruna (QGIS Development Team) and R Studio V.3.6.1 (RStudio, PBC, Boston, Mississippi, USA).

\section{Descriptive and temporal trend analyses}

Age-standardised and sex-standardised prevalence rates per 10000 for all years between 2010 and 2017 were calculated. For data protection reasons, the standardisation was carried out by the KBV using an internal method. Both the prevalence calculation and the weight for standardisation based on the distribution of the statutory health insured population who had received at least one medical treatment in the respective year and met our inclusion criteria. We calculated the mean of prevalence rates on county level ( $\mathrm{N}=402$ counties) with $\mathrm{SD}$, minimum, maximum and the median for each year. Expected values were calculated for each county. A county's expected value represents the prevalence rate that we would expect in accordance with the age and sex composition of the respective county, considering the nationwide prevalence rate for that respective year. In order to identify regional variations for each year of the prevalence of psoriasis, we computed both the extremal quotient (EQ) and the Gini coefficient with associated Lorenz curve for prevalence rates on county level. The EQ is a less precise measurement instrument than the Gini, but the EQ is more suitable for comparison. The EQ is obtained by dividing the maximum identified value in a region, here county, by the minimum value and thus expresses the level of regional differences. ${ }^{14}$ To exclude outliers, we calculated the EQ for values between the 1st percentile and the 99th percentile. The Gini coefficient was initially developed to evaluate economic inequalities ${ }^{15}$ but can also be used in epidemiology to express regional differences in health and healthcare. ${ }^{16-18}$ The associated Lorenz curve graphically describes to which extent the observed distribution deviates from equality. The Gini coefficient ranges from 0 (complete equality) to 1 (complete inequality) and corresponds to the area between the line of equality and the observed Lorenz curve.

For the illustration of the temporal trend of the prevalence rates, we compared the mean prevalence rates of each year and calculated the differences in prevalence rates between 2010 and 2017 for each county. Here, positive values represent an increase and negative values a decrease over time.

\section{Spatial trend analyses, cluster and outlier analyses}

We carried out all analyses for the year 2017. To identify spatial trends in the prevalence of psoriasis, we applied the probability mapping method and a spatial statistical smoothing method. ${ }^{19}$ These methodologies are used complementary to offer a higher validity of the analyses. Both demonstrate a certain kind of relative risk for each county. The probability map illustrates whether the observed value in a region deviates significantly from the mean of all values $(\mathrm{p}<0.05)$ and if so, in which direction. ${ }^{20}{ }^{21}$ For spatial smoothing, we applied an explorative Bayesian procedure with 1000 sequential Monte Carlo iterations. This model takes values of neighbouring counties with a binary adjacency matrix into account, based on the assumption that they have similar characteristics. Smoothed values indicate ratios, with 1 representing the expected value of a county. Counties with values below 1 have lower prevalence rates and vice versa. ${ }^{19} 22{ }^{23} \mathrm{In}$ addition, we examined the relationship between the prevalence rates (standardised and fitted) and the latitude (Universal Transverse Mercator coordinate system; 1 northing equals $1 \mathrm{~m}$ ). For this, correlations of counties' latitude (measured at the centroids of counties) with prevalence rates were calculated using Pearson's $r$ coefficient. Furthermore, we computed linear regressions with the latitude as independent variable and prevalence rates as dependent variables.

To test for autocorrelation, global Moran's I with inversed distances of counties was utilised. The global Moran's I with associated $\mathrm{p}$ value and z-score expresses an aggregate value for all counties and ranges from -1 to 1 . If the $p$ value is significant, autocorrelation is present. ${ }^{24}$ 
Table 1 Mean standardised prevalence of psoriasis on county level per 10000 statutory health insured people

\begin{tabular}{|c|c|c|c|c|c|c|c|c|c|}
\hline & 2010 & 2011 & 2012 & 2013 & 2014 & 2015 & 2016 & 2017 & Change 2010-2017 \\
\hline Mean & 147.4 & 152.8 & 157.0 & 160.7 & 165.8 & 168.6 & 171.9 & 173.5 & +26.1 \\
\hline Median & 145.6 & 149.8 & 152.4 & 155.5 & 161.2 & 162.7 & 166.6 & 168.2 & +24.3 \\
\hline Min & 71.3 & 84.3 & 87.3 & 92.2 & 93.9 & 95.3 & 99.9 & 93.8 & -11.1 \\
\hline Max & 281.8 & 291.4 & 299.7 & 308.3 & 319.3 & 330.1 & 339.6 & 340.9 & +107.1 \\
\hline GC & 0.125 & 0.115 & 0.117 & 0.119 & 0.118 & 0.120 & 0.118 & 0.118 & - \\
\hline
\end{tabular}

$E Q$, extremal quotient; GC, Gini coefficient.

The cluster and outlier analyses include Anselin local Moran's I. It is a relative measure, expresses values for each individual county and indicates whether it is part of a cluster or an outlier. Given a significant $\mathrm{p}$ value, a positive value for I indicates similar values for neighbours, that is, a cluster. High-high clusters are an accumulation of high values, low-low clusters of low values. A negative value for I indicates an outlier. High-low outliers have high values, surrounded by low values, low-high outliers vice versa. ${ }^{25}$

\section{Patient and public involvement}

Patients or the public were not involved in the design, conduct, reporting or dissemination plans of our research.

\section{RESULTS}

\section{Descriptive and temporal trend analyses}

With the M2Q case definition, the total number of psoriasis cases was $\mathrm{N}=1220188$ in 2017 with slightly more women $(51.7 \%)$ affected. The mean standardised prevalence rate in German counties increased from 147.4 per 10000 in 2010 to 173.5 in 2017 (table 1). The EQ remained similar for all years, highest in 2011 with 2.56 and lowest in 2013 with 2.44. The Gini coefficient was highest in 2010 with 0.125 and lowest in 2011 with 0.115 . Figure 1 presents the Lorenz curve of 2017 and its deviation from the line of equality.

Mean prevalence rates for Germany increased each year consistently with an increase of about 3-5 per 10000

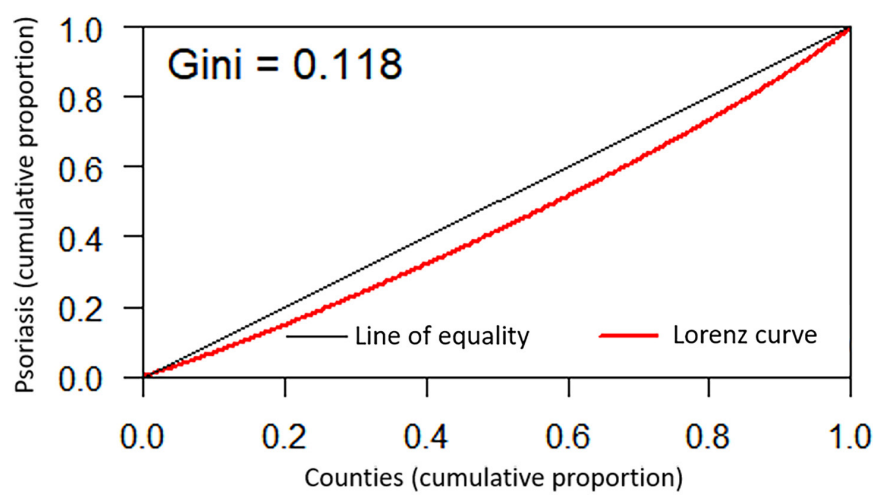

Figure 1 Lorenz curve and Gini coefficient for psoriasis prevalence rates on county level in Germany (2017). (figure 2A). On county level, most counties had increasing prevalence rates between 2010 and 2017. The increases were particularly strong in the eastern regions and some northern counties of Germany. Only few decreasing prevalence rates were observed, most of them in western Germany (figure 2B).

\section{Spatial trend analyses, cluster and outlier analyses}

The probability map shows significantly higher rates in counties in northern and eastern Germany and significantly lower rates in southern Germany, especially in counties of Bavaria and Baden-Württemberg (figure 3A). Counties in central Germany have smoothed prevalence values ranging around 1 , indicating that they are similar to their expected value (figure 3B). Northern counties show increased values, especially in the northeast of Germany. Lower values can be found in the south, in Baden-Württemberg and parts of Bavaria and Rhineland-Palatinate.

The correlation between the latitude of counties and prevalence rates were high, indicating significantly higher prevalence rates in northern counties (figure 4). The fitted values increased by about 24 per 10000 every $100 \mathrm{~km}$ further north, with Pearson's $\mathrm{r}=0.72 \quad(95 \%$ CI 0.57 to $0.76 ; \mathrm{p}<0.05)$. The standardised values increased by about 30 per 10000 every $100 \mathrm{~km}$ further north, with Pearson's $\mathrm{r}=0.65$ (95\% CI 0.58 to $0.70 ; \mathrm{p}<0.05)$.

The global Moran's I value for prevalence rates of 2017 was 0.47 with a $z$-score of 15.8 and a $p$ value of $<0.001$, indicating that autocorrelation is present. The cluster and outlier analyses showed low-low clusters in the regions of Baden-Württemberg, as well as parts of Bavaria, and Rhineland-Palatinate. High-high clusters appear in eastern Germany, as well as parts of Schleswig-Holstein and Lower Saxony. Two high-low outlier regions can be detected in Rhineland-Palatinate, in western Germany. Low-high outliers appear in Berlin and the region of Halle (Saale) in eastern Germany (figure 5).

\section{DISCUSSION}

Regional variations of psoriasis prevalence

The analyses show that there are regional variations of psoriasis prevalence in Germany, independently 
A

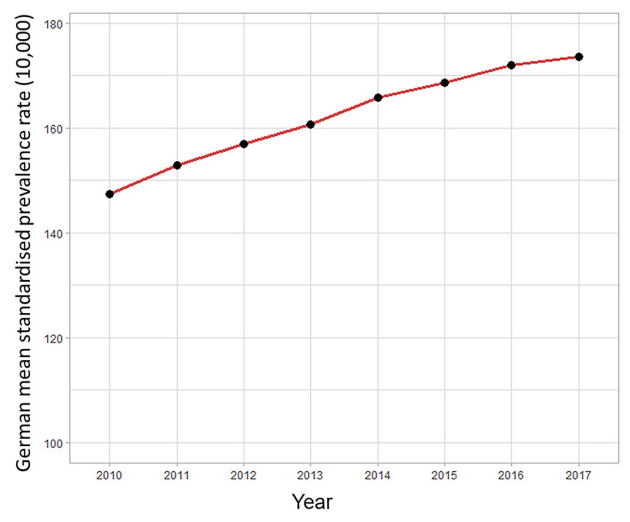

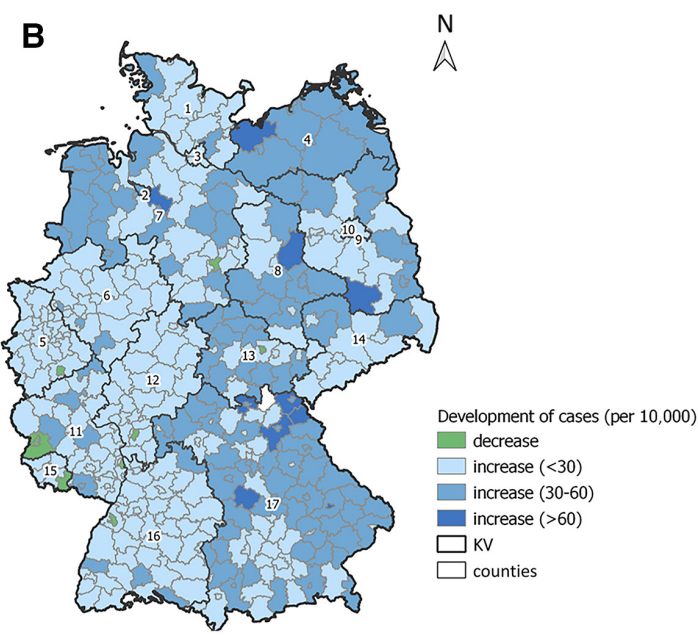

Figure 2 Development of standardised prevalence rates (per 10 000) from 2010 to 2017 in Germany: (A) German mean prevalence rate; (B) prevalence rates on county level in Germany. 1 Schleswig-Holstein; 2 Bremen; 3 Hamburg; 4 MecklenburgWestern Pomerania; 5 North Rhine; 6 Westphalia-Lippe; 7 Lower Saxony; 8 Saxony-Anhalt; 9 Brandenburg; 10 Berlin; 11 Rhineland-Palatinate; 12 Hesse; 13 Thuringia; 14 Saxony; 15 Saarland; 16 Baden-Württemberg; 17 Bavaria. KV, regions of the association of statutory health insurance physicians.

of age and sex distribution of the population. The $\mathrm{EQ}$ and the Gini coefficient do not reveal enormous overall inequality between counties, but along a northsouth gradient inequality becomes visible. The finding of higher prevalence rates in the north is in line with results from the study of Springate $e t a l$, who also showed higher prevalence rates of psoriasis in the northern part of the UK compared with the south, finding a correlation of prevalence rate and latitudes. ${ }^{8}$ Unfortunately, other national studies on regional variations are scarce. However, our results support the worldwide observation of Parisi $e t$ al of a dependency between distance of equator and psoriasis prevalence, with less occurrence near the equator. ${ }^{5}$ Jacobson et al, too, found a weak association between latitude and psoriasis prevalence and suspected ultraviolet radiation (UV) to play a role. ${ }^{9}$ This could also apply to Germany, as UV levels differ within regions. Aside from this environmental factor, sociodemographic structures of the regions may be important as well. A study from Sweden found that the level of deprivation in counties could affect the presence of psoriasis. ${ }^{26}$ Especially in the region of northeastern Germany, several deprived areas exist. For other chronic diseases, such as diabetes or obesity, it has been shown that prevalence rates are higher here ${ }^{27} 28$ and that the overall morbidity is worse. ${ }^{29}$
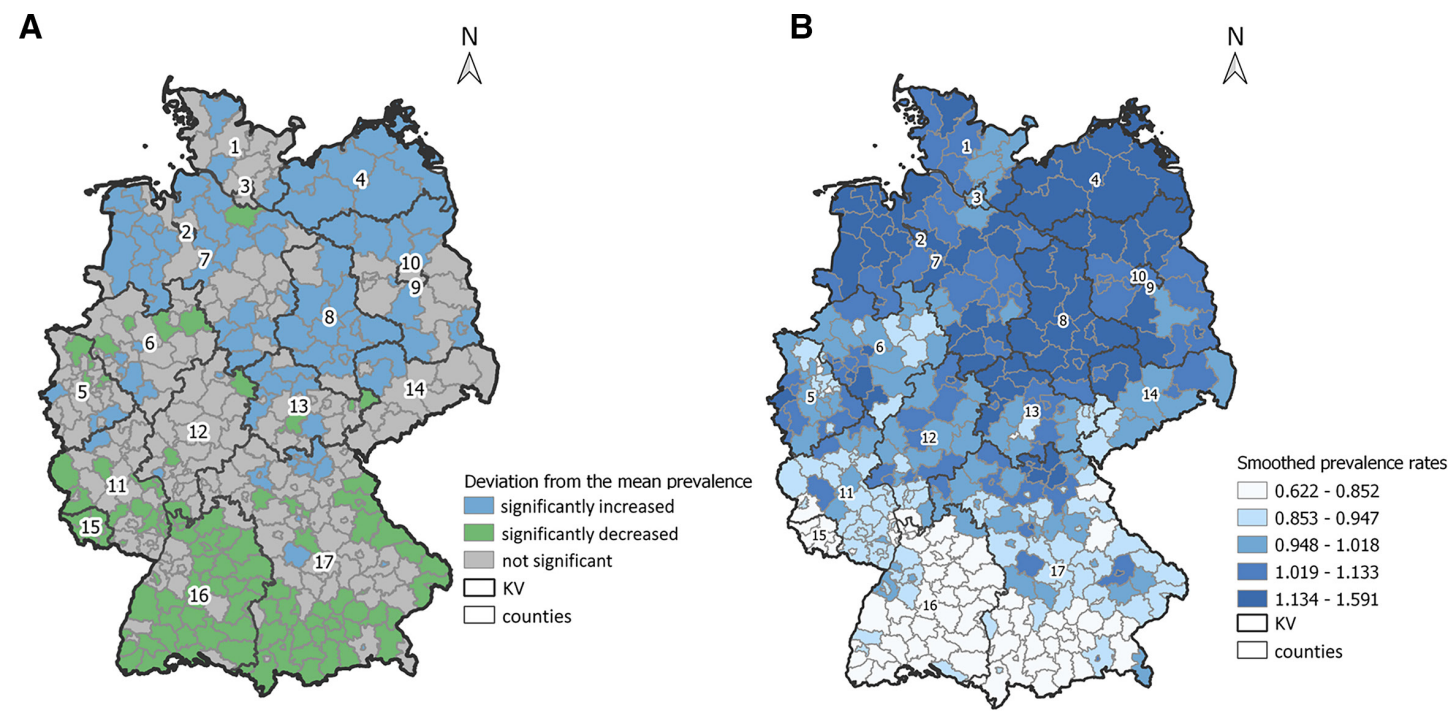

Figure 3 Spatial trends for psoriasis prevalence rates in 2017: (A) German counties with a significant increase or decrease compared with the mean standardised prevalence rate in 2017; (B) smoothed prevalence values for German counties in accordance with Bayes. 1 Schleswig-Holstein; 2 Bremen; 3 Hamburg; 4 Mecklenburg-Western Pomerania; 5 North Rhine; 6 Westphalia-Lippe; 7 Lower Saxony; 8 Saxony-Anhalt; 9 Brandenburg; 10 Berlin; 11 Rhineland-Palatinate; 12 Hesse; 13 Thuringia; 14 Saxony; 15 Saarland; 16 Baden-Württemberg; 17 Bavaria. KV, regions of the association of statutory health insurance physicians. 
A

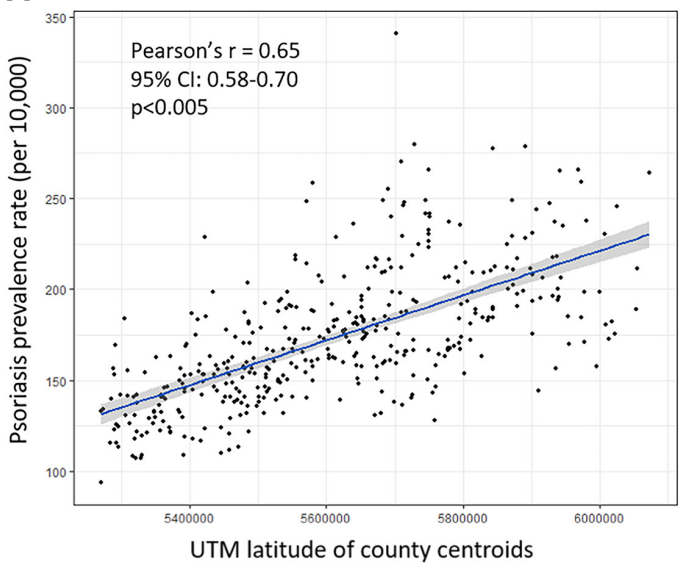

B

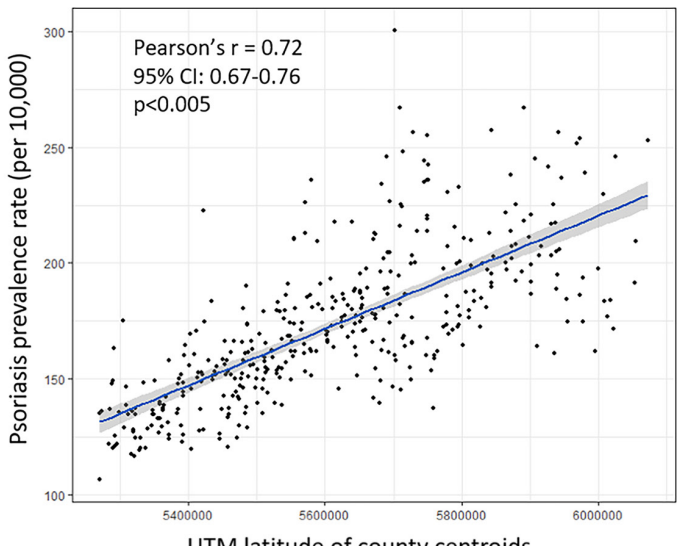

UTM latitude of county centroids

Figure 4 Pearson's correlations of 2017 psoriasis prevalence rates with counties' centroid Universal Transverse Mercator coordinate system (UTM) latitude in Germany: (A) standardised psoriasis prevalence rates (per 10 000); (B) fitted psoriasis prevalence rates (per 10,000).

\section{Increasing prevalence of psoriasis}

We found that psoriasis prevalence rates are increasing in Germany as in several other countries. ${ }^{13}$ However, to investigate reasons for the increase, incidence data for Germany are lacking. Reasons for the prevalence increase could either be an increasing incidence rate or a decreasing mortality rate of psoriasis patients from their comorbidities. Higher billing rates of physicians for psoriasis are also discussed in literature. ${ }^{30}$ With our case

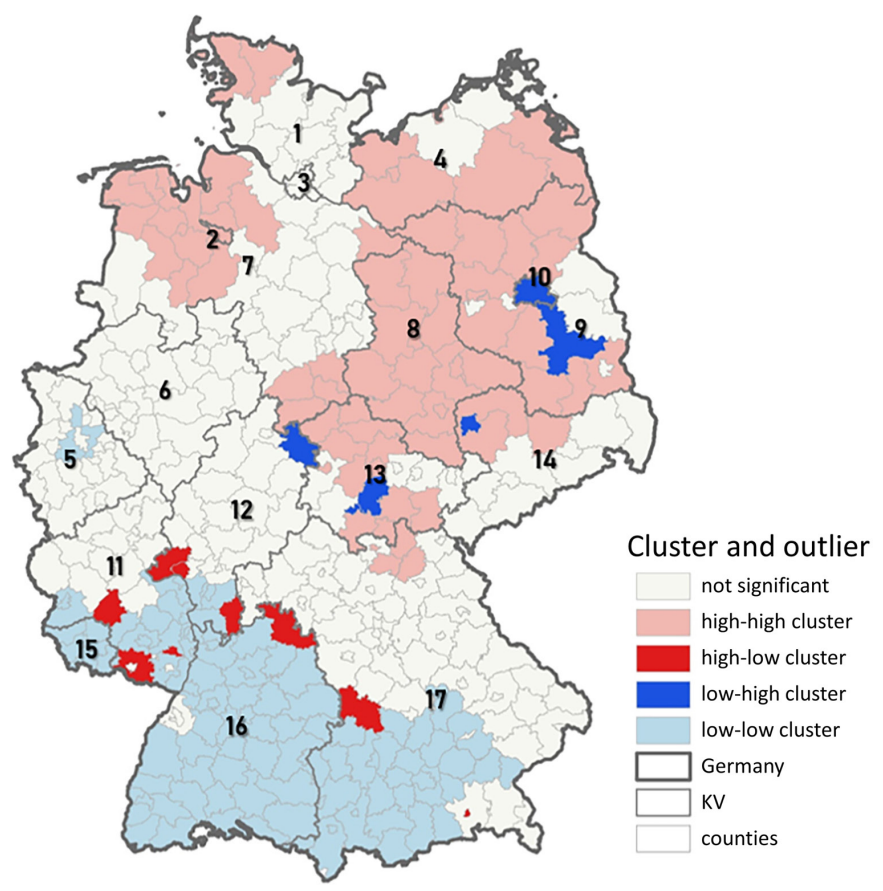

Figure 5 Spatial clusters and outliers for standardised psoriasis prevalence rates in Germany on county level. 1 Schleswig-Holstein; 2 Bremen; 3 Hamburg; 4 MecklenburgWestern Pomerania; 5 North Rhine; 6 Westphalia-Lippe; 7 Lower Saxony; 8 Saxony-Anhalt; 9 Brandenburg; 10 Berlin; 11 Rhineland-Palatinate; 12 Hesse; 13 Thuringia; 14 Saxony; 15 Saarland; 16 Baden-Württemberg; 17 Bavaria. KV, regions of the association of statutory health insurance physicians. definition of at least two billed diagnoses of psoriasis per year, we aimed to avoid an overestimation of those billed diagnoses. The study from the UK suggests that incidence rates seem to be stable and people tend to live longer with the disease. ${ }^{8}$ But regardless of the reason, it is important that decision makers are aware of the increase and can adapt if necessary.

\section{Strengths and limitations}

This study contributes to psoriasis research with a unique database that largely represents the German population over an 8-year period. In addition, it is the first study known to us that examines regional variations of psoriasis in Germany and among few internationally. We applied various statistical and geographical methods thoroughly to examine the regional patterns from different perspectives. Though, some limitations need to be addressed. For data protection reasons, the standardisation was carried out by the data provider using an internal method. In addition, we did not have access to the raw data for the same reasons, so the best possible approach to calculate the national prevalence rates was to calculate a nationwide average. Unfortunately, this fact can make comparisons with other international studies more difficult. We have no access to incidence rates and cannot fully explain why the prevalence is rising. In comparison to other prevalence studies in Germany, this study detected lower prevalence rates of $1.47 \%-1.74 \%$, possibly due to our stricter case definition. ${ }^{30-35}$ This definition possibly excluded mild cases, but also allowed us to better align different coding patterns in the regions. In addition, we rely on billing data and cannot validate this data. The level of counties in Germany has the disadvantage that the size and composition of the population can be very heterogeneous. In rare diseases, cases in small counties can therefore generate outliers and hamper interpretation. Yet for psoriasis we had enough cases per county and the use of standardised rates as well as the smoothing process prevented the overestimation of outliers. However, when 
interpreting the results, the ecological fallacy must be taken into account. The results generated here are based on aggregated data and cannot directly be related to the individual.

\section{CONCLUSION}

The results show increasing prevalences of psoriasis in Germany. However, significant differences in standardised prevalence rates across the country exist with high rates in northern and eastern Germany. With regard to the care of psoriasis, reasons for the variations still need to be determined in detail. Since psoriasis is often accompanied by severe comorbidities, it is for instance important to investigate whether their prevalence rates are also increasing and vary regionally. This could indicate a greater need for treatment.

Acknowledgements We thank the National Association of Statutory Health Insurance Physicians (German: Kassenärztliche Bundesvereinigung, KBV) in Germany for providing and processing the ambulatory care claims data. In addition, we would like to thank the Scientific Communication Team of the IVDP, in particular Merle Twesten and Mario Gehoff, for copyediting.

Contributors The contributors VA and JA had full access to all data in this study and take responsibility for the integrity and accuracy of the data analysis. They were also responsible for the study concept and design. VA, SW, MA, NM and $J A$ were involved in the interpretation and preparation of the manuscript as well as the critical review. VA and JA revised the content of the manuscript. VA, JA and SW were involved in the statistical analysis. JA and MA were responsible for administrative, technical or material support. JA is responsible for the overall content.

Funding The authors have not declared a specific grant for this research from any funding agency in the public, commercial or not-for-profit sectors.

Map disclaimer The depiction of boundaries on the map(s) in this article do not imply the expression of any opinion whatsoever on the part of BMJ (or any member of its group) concerning the legal status of any country, territory, jurisdiction or area or of its authorities. The map(s) are provided without any warranty of any kind, either express or implied.

\section{Competing interests None declared.}

Patient and public involvement Patients and/or the public were not involved in the design, conduct, reporting or dissemination plans of this research.

Patient consent for publication Not applicable.

Provenance and peer review Not commissioned; externally peer reviewed.

Data availability statement Data are available on reasonable request. The datasets used and/or analysed during the current study are available from the corresponding author on reasonable request.

Open access This is an open access article distributed in accordance with the Creative Commons Attribution Non Commercial (CC BY-NC 4.0) license, which permits others to distribute, remix, adapt, build upon this work non-commercially, and license their derivative works on different terms, provided the original work is properly cited, appropriate credit is given, any changes made indicated, and the use is non-commercial. See: http://creativecommons.org/licenses/by-nc/4.0/.

ORCID iD

Jobst Augustin http://orcid.org/0000-0003-1541-2369

\section{REFERENCES}

1 WHO. Global report on psoriasis, 2016

2 Gelfand JM, Troxel AB, Lewis JD, et al. The risk of mortality in patients with psoriasis. Arch Dermatol 2007;143.

3 Danielsen K, Olsen AO, Wilsgaard T, et al. Is the prevalence of psoriasis increasing? A 30-year follow-up of a population-based cohort. Br J Dermatol 2013;168:1303-10.
4 Michalek IM, Loring B, John SM. A systematic review of worldwide epidemiology of psoriasis. J Eur Acad Dermatol Venereol 2017;31:205-12.

5 Parisi R, Symmons DPM, Griffiths CEM, et al. Global epidemiology of psoriasis: a systematic review of incidence and prevalence. $J$ Invest Dermatol 2013;133:377-85.

6 Parisi R, Iskandar IYK, Kontopantelis E, et al. National, regional, and worldwide epidemiology of psoriasis: systematic analysis and modelling study. BMJ 2020;369:m1590.

7 Enamandram M, Kimball AB. Psoriasis epidemiology: the interplay of genes and the environment. J Invest Dermatol 2013;133:287-9.

8 Springate DA, Parisi R, Kontopantelis E, et al. Incidence, prevalence and mortality of patients with psoriasis: a U.K. population-based cohort study. Br J Dermatol 2017;176:650-8.

9 Jacobson CC, Kumar S, Kimball AB. Latitude and psoriasis prevalence. J Am Acad Dermatol 2011;65:870-3. doi:10.1016/j. jaad.2009.05.047

10 Saraceno R, Mannheimer R, Chimenti S. Regional distribution of psoriasis in Italy. J Eur Acad Dermatol Venereol 2008;22:324-9.

11 Kirby RS, Delmelle E, Eberth JM. Advances in spatial epidemiology and geographic information systems. Ann Epidemiol 2017;27:1-9.

12 Shaw N, McGuire S. Understanding the use of geographical information systems (GIS) in health informatics research: a review. $J$ Innov Health Inform 2017;24:228.

13 GKV-Spitzenverband. Statutory health insurance, 2019. Available: https://www.gkv-spitzenverband.de/english/statutory_health insurance/statutory_health_insurance.jsp [Accessed 05 Mar 2020].

14 Ibáñez B, Librero J, Bernal-Delgado $\mathrm{E}$, et al. Is there much variation in variation? revisiting statistics of small area variation in health services research. BMC Health Serv Res 2009;9:60.

15 Gini C. On the measurement of concentration and variability of characters. Int J Stat 2005; LXIII:3-38.

16 Duarte EC, Ramalho WM, Tauil PL, et al. The changing distribution of malaria in the Brazilian Amazon, 2003-2004 and 2008-2009. Rev Soc Bras Med Trop 2014;47:763-9.

17 Lee WC. Characterizing exposure-disease association in human populations using the Lorenz curve and Gini index. Stat Med 1997;16:729-39.

18 Wang W, He M, Li Z, et al. Epidemiological variations and trends in health burden of glaucoma worldwide. Acta Ophthalmol 2019;97:e349-55.

19 Besag J, York J, Mollié A. Bayesian image restoration, with two applications in spatial statistics. Ann Inst Stat Math 1991;43:1-20.

20 Dreesmann J. Räumlich-statisticshe Analyse von epidemiologischen Daten. In: Augustin J, Koller D, eds. Geographie der Geusndheit: die räumliche dimension von Epidemiologie und Versorgung. 1st edn. Bern: Hogrefe, 2017: 48-66.

21 Cressie NA. Statistics for spatial data, revised ed. New York: Wiley, 1993.

22 Duncan EW, White NM, Mengersen K. Spatial smoothing in Bayesian models: a comparison of weights matrix specifications and their impact on inference. Int J Health Geogr 2017;16:47.

23 Cressie N. Smoothing regional maps using empirical Bayes predictors. Geogr Anal 1992;24:75-95.

24 ESRI. Funktionsweise von räumlicher Autokorrelation (Global Moran's I). Available: https://pro.arcgis.com/de/pro-app/tool-reference/ spatial-statistics/h-how-spatial-autocorrelation-moran-s-i-spatial-st. htm [Accessed 05 Mar 2020].

25 ESRI. Cluster and Outlier Analysis (Anselin Local Moran's I). Available: https://desktop.arcgis.com/en/arcmap/latest/tools/spatialstatistics-toolbox/cluster-and-outlier-analysis-anselin-local-moran-s. $\mathrm{htm}$

$26 \mathrm{Li} \mathrm{X}$, Sundquist J, Hamano T, et al. Neighborhood deprivation and risks of autoimmune disorders: a national cohort study in Sweden. Int J Environ Res Public Health 2019;16. doi:10.3390/ijerph16203798. [Epub ahead of print: 09 Oct 2019].

27 Maier W, Holle R, Hunger M, et al. The impact of regional deprivation and individual socio-economic status on the prevalence of Type 2 diabetes in Germany. A pooled analysis of five population-based studies. Diabet Med 2013;30:e78-86.

28 Prütz F, Rommel A, Kroll LE. 25 years after the fall of the Berlin wall: regional differences in health. Robert Koch-Institut, 2014.

29 Mielck A. Comparison of health inequalities between East and West Germany. Eur J Public Health 2000;10:262-7.

30 Icen M, Crowson CS, McEvoy MT, et al. Trends in incidence of adultonset psoriasis over three decades: a population-based study. J Am Acad Dermatol 2009;60:394-401.

31 Schäfer I, Rustenbach SJ, Radtke M, et al. Epidemiologie der Psoriasis in Deutschland - Auswertung von Sekundärdaten einer gesetzlichen Krankenversicherung. Gesundheitswesen 2011;73:308-13. 
32 Zander N, Schäfer I, Radtke M, et al. Dermatological comorbidity in psoriasis: results from a large-scale cohort of employees. Arch Dermatol Res 2017;309:349-56.

33 Augustin M, Herberger K, Hintzen S, et al. Prevalence of skin lesions and need for treatment in a cohort of 90880 workers. $\mathrm{Br} \mathrm{J}$ Dermatol 2011;165:865-73.
34 Augustin M, Reich K, Glaeske G, et al. Co-morbidity and agerelated prevalence of psoriasis: analysis of health insurance data in Germany. Acta Derm Venereol 2010;90:147-51.

35 Augustin M, Glaeske G, Radtke MA, et al. Epidemiology and comorbidity of psoriasis in children. $\mathrm{Br} \mathrm{J}$ Dermatol 2010;162:633-6. 